\title{
NOTES ON THE HERZ-TYPE HARDY SPACES OF VARIABLE SMOOTHNESS AND INTEGRABILITY
}

\section{DOUADI DRIHEM AND FAKHREDDINE SEGHIRI}

Abstract. The aim of this paper is twofold. First we give a new norm equivalents of the variable Herz spaces $K_{p(\cdot), q(\cdot)}^{\alpha(\cdot)}\left(\mathbb{R}^{n}\right)$ and $\dot{K}_{p(\cdot), q(\cdot)}^{\alpha(\cdot)}\left(\mathbb{R}^{n}\right)$. Secondly we use these results to prove the atomic decomposition for Herz-type Hardy spaces of variable smoothness and integrability. Also, we prove the boundedness of a wide class of sublinear operators on these spaces, which includes maximal, potential and Calderón-Zygmund operators.

Mathematics subject classification (2010): 42B20, 42B35, 46E30.

Keywords and phrases: Herz-type Hardy space, atom, variable exponent, sublinear operator.

\section{REFERENCES}

[1] A. Almeida AND P. HÄstö, Besov spaces with variable smoothness and integrability, J. Funct. Anal. 258 (2010), 1628-1655.

[2] A. Almeida AND D. Drinem, Maximal, potential and singular type operators on Herz spaces with variable exponents, J. Math. Anal. Appl. 394 (2012), 781-795.

[3] A. BAernstein II AND E. T. SAWYeR, Embedding and multiplier theorems for $H^{p}\left(\mathbb{R}^{n}\right)$, Mem. Amer. Math. Soc. 53, no. 318, 1985.

[4] Y. CHEN, S. LEVINE AND R. RAO, Variable exponent, linear growth functionals in image restoration, SIAM J. Appl. Math. 66 (2006), no. 4, 1383-1406.

[5] D. Drinem, Embeddings properties on Herz-type Besov and Triebel-Lizorkin spaces, Math. Ineq and Appl. 16, 2 (2013), 439-460.

[6] D. DRIHEM, Some properties of variable Besov-type spaces, Funct. Approx. Comment. Math 52, 2 (2015), 193-221.

[7] L. Diening, P. Harjulehto, P. HÄstö And M. RŮŽIČKA, Lebesgue and Sobolev Spaces with Variable Exponents, Lecture Notes in Mathematics, vol. 2017, Springer-Verlag, Berlin, 2011.

[8] B. Dong And J. Xu, New Herz type Besov and Triebel-Lizorkin spaces with variable exponents, J. Funct. Spaces Appl. Volume 2012 (2012), Article ID 384593, 27 pages.

[9] B. Dong And J. Xu, Herz-Morrey type Besov and Triebel-Lizorkin spaces with variable exponents, Banach J. Math. Anal. 9, 1 (2015), 75-101.

[10] H. G. Feichtinger And F. Weisz, Herz spaces and summability of Fourier transforms, Math. Nachr. 281, 3 (2008), 309-324.

[11] C. HERZ, Lipschitz spaces and Bernstein's theorem on absolutely convergent Fourier transforms, J. Math. Mech. 18 (1968), 283-324.

[12] M. IZUKI, Herz and amalgam spaces with variable exponent, the Haar wavelets and greediness of the wavelet system, East. J. Approx. 15 (2009), 87-109.

[13] M. IZUKI, Boundedness of sublinear operators on Herz spaces with variable exponent and application to wavelet characterization, Anal. Math. 36 (2010), 33-50.

[14] M. IZUKI AND T. NOI, Boundedness of some integral operators and commutators on generalized Herz spaces with variable exponents, http://www.sci.osaka-cu.ac.jp/math/OCAMI/preprint/ 2011/11-15.pdf.

[15] H. KempKa AND J. VybíRAL, A note on the spaces of variable integrability and summability of Almeida and Hästö, Proc. Amer. Math. Soc. 141, 9 (2013), 3207-3212. 
[16] X. Li AND D. YAng, Boundedness of some sublinear operators on Herz spaces, Illinois J. Math. 40 (1996), 484-501.

[17] Y. Liang, D. Yang And C. Zhuo, Intrinsic Square Function Characterizations of Hardy Spaces with Variable Exponents, Bull. Malays. Math. Sci. Soc, to appear.

[18] S. LU AND D. YAng, The decomposition of weighted Herz space on $\mathbb{R}^{n}$ and its applications, Sci. China (Ser. A) 38 (1995), 147-158.

[19] Z. LiU AND H. WANG, The Herz-type Hardy spaces with variable exponent and thier applications, Taiwanese. J. Math. 16, 4 (2012), 1363-1389.

[20] M. A. Ragusa, Homogeneous Herz spaces and regularity results, Nonlinear Anal. 71 (2009), 1-6.

[21] M. A. RAgus A, Parabolic Herz spaces and their applications, Appl. Math. Lett. 25, 10 (2012), 12701273.

[22] M. RŮŽIČKA, Electrorheological fluids: modeling and mathematical theory, Lecture Notes in Mathematics, 1748, Springer-Verlag, Berlin, 2000.

[23] S. S Aмко, Variable exponent Herz spaces, Mediterr. J. Math. 10, 4 (2013), 2007-2025.

[24] C. SHI AND J. Xu, Herz type Besov and Triebel-Lizorkin spaces with variable exponent, Front. Math. China. 8, 4 (2013), 907-921.

[25] F. SORIA AND G. WeISS, A remark on singular integrals and power weights, Indiana Univ. Math. J. 43 (1994), 187-204.

[26] J. XU AND X. YAng, Herz-Morrey-Hardy Spaces with Variable exponents and Their Applications, J. Funct. Spaces Appl. Volume 2015 (2015), Article ID 160635, 19 pages.

[27] J. Xu, Decompositions of non-homogeneous Herz type Besov and Triebel-Lizorkin spaces, Sci. China. Math. 57, 2 (2014), 315-331. 